\title{
Lycophyta da borda oeste do Pantanal, Mato Grosso do Sul, Brasil
}

\author{
Elton Luis Monteiro de Assis ${ }^{1}$ e Paulo Henrique Labiak ${ }^{1,2}$
}

Recebido em 14/03/2008. Aceito em 23/10/2008

RESUMO - (Lycophyta da borda oeste do Pantanal, Mato Grosso do Sul, Brasil). Este trabalho apresenta o tratamento taxonômico para as espécies de Lycophyta da região da borda oeste do Pantanal sul-matogrossense. Duas famílias estão presentes na área, Lycopodiaceae e Selaginellaceae, com cinco e seis espécies respectivamente. São apresentadas chaves de identificação, descrições das famílias, gêneros e espécies, ilustrações, bem como dados sobre a distribuição geográfica e comentários sobre as espécies mais semelhantes.

Palavras-chave: licófitas, Lycopodiaceae, Pantanal, Selaginellaceae, taxonomia

ABSTRACT - (Lycophyta from the western Pantanal, Mato Grosso do Sul State, Brazil). We present a taxonomic treatment of the Lycophyta species from the western border of the Brazilian Pantanal. Two families are present in this area, Lycopodiaceae and Selaginellaceae, with five and six species, respectively. Identification keys, descriptions of the families, genera and species, illustrations, geographic distribution, and comments on the closest species are presented.

Key words: lycophytes, Lycopodiaceae, Pantanal, Selaginellaceae, taxonomy

\section{Introdução}

A divisão Lycophyta constitui a linhagem mais basal das plantas terrestres vasculares (Pryer et al. 2001). Dentre as diversas sinapormorfias que definem este grupo, pode-se citar as folhas uninervadas (microfilos) e os esporângios adaxiais com deiscência transversal (Cantino et al. 2007).

Atualmente o grupo é constituído por três famílias, sendo que apenas Isoëtaceae não possui representantes na região estudada, apesar de estar representada nas planícies de inundação do Pantanal brasileiro por apenas uma espécie até o momento, Isoëtes pedersenii H.P. Fuchs ex Hickey, citado por Pott \& Pott (1997; 2000) com ocorrência nas regiões da Nhecolândia e Abobral no limite leste da área de estudo. Embora esta família seja exclusivamente de hábito aquático, sua ocorrência é verificada em regiões de altitude elevada e com clima mais frio, estando ausente na região da borda oeste do Pantanal brasileiro. Desta forma, são tratadas neste trabalho as espécies pertencentes às duas famílias restantes, Lycopodiaceae e Selaginellaceae.

Lycopodiaceae é uma família com cerca de 450 espécies, distribuídas em praticamente todos os continentes, das quais aproximadamente 250 estão presentes na região Neotropical (Øllgaard 1995). De acordo com a classificação de Øllgaard (1987), a família é dividida em quatro gêneros, Huperzia Bernh., Lycopodiella Holub, Lycopodium L. e o gênero monotípico Phylloglossum Kunze, sendo que destes, apenas o último não ocorre no Brasil.

Para o Brasil se destacam os trabalhos de Nessel (1927; 1955), nos quais são considerados 103 e 105 táxons, respectivamente. Mais recentemente, Øllgaard \& Windisch (1987) apresentaram uma sinopse das Licopodiáceas do Brasil, citando a ocorrência de 52 espécies para a flora brasileira. Neste mesmo trabalho, os autores apresentam uma revisão bastante crítica das obras de Nessel, resultando em uma diminuição no número de táxons considerados para o Brasil.
Selaginellaceae, por sua vez, é uma família com cerca de 700 espécies, também amplamente distribuída nas regiões tropicais (Fraile 1995). A família apresenta apenas um gênero, claramente monofilético segundo as análises moleculares recentes (Korall \& Kenrich 2002; Korall et al. 1999).

Um dos estudos mais abrangentes sobre a taxonomia de Selaginella foi apresentado por Alston et al. (1981) e, mais recentemente, destaca-se o trabalho de Hirai \& Prado (2000) para o Estado de São Paulo.

Desta forma, o presente trabalho apresenta o tratamento taxonômico para uma área ainda pouco explorada do território brasileiro, com chaves de identificação, descrições, comentários e ilustrações, de maneira que possa auxiliar não só na identificação das espécies presentes na borda oeste do Pantanal, mas também em áreas adjacentes do Brasil Central, Bolívia e Paraguai.

\section{Material e métodos}

A área de estudo, denominada borda oeste do Pantanal, situa-se na bacia do Alto Paraguai, nos municípios de Corumbá, Ladário e Porto Murtinho-MS, entre as coordenadas $17^{\circ} 24^{\prime}$ e $19^{\circ} 25^{\prime} \mathrm{S}$ e $57^{\circ} 22^{\prime}$ e $57^{\circ} 58^{\prime} \mathrm{W}$. É limitada a Oeste pela fronteira entre o Brasil e a Bolívia, a Leste pelas regiões da Nhecolândia e Paiaguás, ao Norte pelos morros residuais pertencentes às morrarias do Amolar, na divisa com o Estado de Mato Grosso, e ao Sul de Corumbá pelo Maciço do Urucum e de Coimbra.

Os ambientes encontrados na região são bastante distintos, variando desde planícies de inundação, contendo vegetação inundável com áreas de matas ciliares, até morrarias de $1.065 \mathrm{~m}$ de altitude com diferentes tipologias vegetacionais como florestas semideciduais e deciduais, cerradão e campos de altitude (Bortolotto et al. 1999), além de incorporar elementos das províncias fitogeográficas adjacentes, como a Floresta Amazônica e o Chaco (Adamoli 1982).

Os materiais foram coletados entre os anos de 2004 a 2006, segundo as técnicas padrões para o grupo, e depositados nos herbários COR e UPCB. Duplicatas, quando disponíveis, foram enviadas aos herbários BHCB, MBM, SI e SP, também foram analisados materiais anteriormente depositados nos herbários COR e CPAP de Corumbá e USZ da Bolívia.

Os basiônimos, bem como as informações sobre a distribuição geográfica, foram baseados em literatura especializada e em observações dos próprios autores. A abreviação dos autores de nomes de espécies segue Pichi-Sermolli (1996).

\footnotetext{
1 Universidade Federal do Paraná, Programa de Pós-Graduação em Botânica, Curitiba, PR, Brasil

2 Autor para correspondência: plabiak@ufpr.br
} 


\section{Resultados e discussão}

Foram encontradas 11 espécies de Lycophyta, cinco pertencentes à família Lycopodiaceae (Huperzia 2 spp. e Lycopodiella 3 spp.) e seis à família Selaginellaceae (único gênero Selaginella). De uma maneira geral, as espécies se encontram distribuídas nas formações montanhosas do Pantanal, demonstrando a grande influência dessas formações na riqueza de espécies na bacia do rio Paraguai. Das espécies encontradas merece destaque $S$. chiquitana, uma espécie recentemente descrita para a Bolívia (Kessler et al. 2006), a qual é aparentemente endêmica das formações montanhosas do Chaco e da borda oeste do Pantanal. As demais, por sua vez, são espécies com ampla distribuição geográfica no Brasil.

Chave para as famílias de Lycophyta da borda oeste do Pantanal sul-matogrossense

1. Microfilos sem lígula; estróbilos, quando presentes, cilíndricos em corte transversal; plantas homosporadas ........................... Lycopodiaceae

1. Microfilos ligulados; estróbilos quadrangulares em corte transversal; plantas heterosporadas Selaginellaceae

Lycopodiaceae Mirb. in Lam. \& Mirb., Hist. Nat. Veg. 4: 293. 1802.

Plantas terrícolas, rupícolas ou epífitas. Caule ereto, pendente ou prostrado, curto a longo-reptante, dicotomicamente ramificado ou com ramificações laterais, glabro ou com tricomas unicelulares, hialinos; microfilos dispostos espiraladamente, em espiral irregulares ou alternos, isofilos ou heterofilos; esporofilos não ligulados semelhantes aos microfilos ou modificados, às vezes especializados e agregados em estróbilos distintos, cilíndricos em corte transversal, localizados no ápice dos ramos; esporângios glabros, solitários, situados nas axilas dos esporofilos, reniformes a globulares, curtamente pedunculados, deiscentes por aberturas transversais que dividem cada esporângio em 2 valvas, isovalvados ou anisovalvados; esporos triletes, homospóricos, amarelos, faveolados. $x=11,23,34,35$, $39,67,68,78,104$.

Chave para os gêneros de Lycopodiaceae da borda oeste do Pantanal sul-matogrossense

1. Caule dicotomicamente ramificado, sem um ramo principal definido; esporofilos semelhantes aos microfilos, às vezes menores, raramente agregados em estróbilos distintos

1. Huperzia

1. Caule com ramificações laterais, com um ramo principal definido; esporofilos diferentes dos microfilos, agregados em estróbilos distintos

2. Lycopodiella
1. Huperzia Bernh., J. Bot. (Schrad.) 1800(2): 126. 1801. Tipo: Huperzia selago (L.) Schrank \& Mart.

Plantas epífitas ou terrícolas. Caule ereto ou pendente, dicotomicamente ramificado, sem um ramo principal definido, glabro; microfilos linear-lanceolados a oblanceolados, dispostos espiraladamente sobre o caule; esporofilos linearlanceolados a oblanceolados, semelhantes aos microfilos ou ligeiramente menores, raramente agregados em estróbilos distintos; esporângios glabros, solitários, situados nas axilas dos esporofilos, inseridos basalmente no lado acroscópico, 1-loculares, reniformes, curtamente pedunculados, deiscentes por aberturas transversais que divide cada esporângio em 2 valvas, isovalvados; esporos triletes, homospóricos, amarelos, faveolados.

Huperzia é um gênero cosmopolita com cerca de 400 espécies (Øllgaard 1995), ocorrendo nos trópicos, regiões temperadas e subpolares, com o seu centro de diversidade na América tropical (Tryon \& Tryon 1982), crescendo preferencialmente nas florestas perenifólias de regiões montanhosas e nos páramos e subpáramos dos Andes (Øllgaard \& Windisch 1987). De acordo com estes mesmos autores, no Brasil ocorrem cerca de 37 espécies, 23 destas endêmicas da Serra do Mar.

Na região da borda oeste do Pantanal sul-matogrossense foram registradas duas espécies, ocorrendo em regiões montanhosas no interior de Florestas Estacionais Semideciduais, ou como terrícolas em locais abertos nas encostas de morros.

Chave para as espécies de Huperzia da borda oeste do Pantanal sul-matogrossense

1. Plantas epífitas; caule 4 a 8 vezes dicotomicamente furcado; microfilos lineares, com base avermelhada, ascendentes.

\section{H. mandiocana}

1. Plantas terrícolas ou rupícolas; caule 1 a 2 vezes dicotomicamente furcado; microfilos linear-lanceolados, com base esverdeada, deflexos 2. H. reflexa

1. Huperzia mandiocana (Raddi) Trevis., Atti Soc. Ital. Sci. Nat. 17: 248. 1874.

Lycopodium mandiocanum Raddi, Opusc. Sci. Bolon. 3: 280. 1819.

Fig. 1

Plantas epífitas, eretas ou mais raramente pendentes, ca. $25 \mathrm{~cm}$ compr. Caule 4-8 vezes dicotomicamente furcado, ca. 5 mm diâm., estramíneo a castanho-claro, avermelhado na região de inserção dos microfilos; microfilos isofilos, arranjados em verticilos irregulares, lineares, $0,6-2,5 \mathrm{~cm}$ compr. $\times 0,1-0,12 \mathrm{~cm}$ larg., cartáceos, com dois sulcos na face adaxial, as vezes ausentes, ápice longo-acuminado, base alargada, avermelhada, esparsamente pilosa, margem inteira; microfilos proximais deflexos ou patentes, os distais fortemente ascendentes; esporofilos semelhantes aos 
microfilos, às vezes menores; esporângios evidentes.

Material examinado: BRASIL. Mato Grosso do Sul: Corumbá, Morro Santa Cruz (MCR), 19²4'49'”S e 59²2'47' 'W, 29/V/1999, E.L.M. Assis \& D. Rodriguez 08 (BHCB, COR); 10/X/2003, E.L.M. Assis et al. 452 (COR, MBM, UPCB).

Material adicional examinado: BOLÍVIA. Santa Cruz:

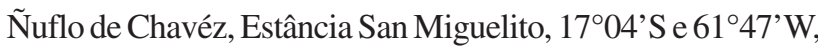
14/V/1995, L. Fuentes 437 (USZ).

Distribuição geográfica: Bolívia, Paraguai, Argentina e Brasil (BA, MG, MS, ES, RJ, SP, PR, SC, RS).

Huperzia mandiocana se caracteriza por apresentar os microfilos lineares geralmente com dois sulcos na face adaxial e principalmente com a base alargada, avermelhada, e a margem inteira.

Assemelha-se a Huperzia wilsonii (Underw. \& F. E. Lloyd) B. Øllg., uma espécie presente no Estado do Mato Grosso, a qual pode ser distinguida pelo diâmetro do caule menor (de 1-2 mm, excluindo-se os microfilos), e esporofilos sem a base alargada (Øllgaard \& Windisch 1987). Na região H. mandiocana ocorre em Florestas Estacionais Semideciduais e acima de $800 \mathrm{~m}$ de altitude.

2. Huperzia reflexa (Lam.) Trevis., Atti Soc. Ital. Sci. Nat. 17:248. 1874.

Lycopodium reflexum Lam., Encycl. Méthodique Bot. 3: 653. 1789.

Fig. 2-3

Plantas terrícolas ou rupícolas, eretas, ca. $15 \mathrm{~cm}$ compr. Caule simples a 1-2-furcado, ca. 1,3 mm diâm., estramíneo, não avermelhado na região de inserção dos microfilos; microfilos isofilos, arranjados espiraladamente, linearlanceolados, 3,0-4,0 mm compr. ×1,0-2,0 mm larg., coriáceos, não sulcados, ápice acuminado, base glabra, alargada, não avermelhada, margem denticulada, microfilos proximais fortemente deflexos, os distais ascendentes, subadpressos; esporofilos semelhantes aos microfilos; esporângios evidentes.

Material examinado: BRASIL. Mato Grosso do Sul: Corumbá, Morro Santa Cruz, $19^{\circ} 24^{\prime} 49^{\prime \prime}$ S e 59²2'47'W, 30/VIII/1999, E.L.M. Assis et al. 48 (BHCB, COR).

Material adicional examinado: BOLÍVIA. Chuquisaca: $\mathrm{H}$. Siles, 2/X/1983, L. Liberman s.n (USZ).

Distribuição geográfica: México, Guatemala, Belize, Honduras, Salvador, Nicarágua, Costa Rica, Panamá, Antilhas, Colômbia, Venezuela, Trinidad, Equador, Peru, Bolívia, Paraguai e Brasil (MG, MS, RJ, SP, PR, SC, RS).

Esta espécie se caracteriza por apresentar os microfilos linear-lanceolados, fortemente deflexos e a margem denticulada, características que a distingue $H$. mandiocana.

H. reflexa ocorre em cerradões principalmente como rupícola em encostas de morros ou locais acidentados, acima de $800 \mathrm{~m}$ de altitude.

2. Lycopodiella Holub, Preslia 36: 22. 1964. Tipo: Lycopodiella inundata (L.) Holub.
Plantas terrícolas ou raramente rupícolas. Caule ereto com ramificações laterais, com estolão horizontal na base, ou horizontal, com um ramo ereto não ramificado, curto a longoreptante, glabro ou com tricomas unicelulares, hialinos; microfilos lanceolados, dispostos espiraladamente ao redor do caule; esporofilos deltóides a linear-lanceolados, distintos dos microfilos, agregados em estróbilos distintos localizados no ápice dos ramos, não ligulados; esporângios glabros, solitários, situados nas axilas dos esporofilos ou no lado superior da base dos esporofilos, uniloculares, globulares, curtamente pedunculados, deiscentes por uma abertura transversal que divide cada esporângio em 2 valvas, isovalvados ou fortemente anisovalvados; esporos triletes, homospóricos, amarelos, faveolados.

Lycopodiella é um gênero com cerca de 40 espécies, com seu centro de diversidade na América tropical. No Brasil ocorrem cerca de oito espécies e cinco variedades, crescendo em solos úmidos e brejosos de regiões montanhosas (Øllgaard \& Windisch 1987)

Na região da borda oeste do Pantanal sul-matogrossense foram registradas três espécies, ocorrendo principalmente como terrícolas em áreas de cerradões, encostas de morros ou locais paludosos próximos a cursos d'água.

Chave para as espécies de Lycopodiella da borda oeste do Pantanal sul-matogrossense

1. Caule prostrado; estróbilos eretos situados no ápice de um ramo ereto; microfilos dimorfos 2. L. caroliniana

1. Caule ereto; estróbilos pendentes situados no ápice dos ramos laterais; microfilos monomorfos

2. Ramos laterais ascendentes, dicotomicamente ramificados, ramos e base dos microfilos com densos tricomas, ca. $1,5 \mathrm{~mm}$ compr. 1. L. camporum

2. Ramos laterais patentes, pinadamente ramificados, ramos glabros, base dos microfilos glabros ou com esparsos tricomas unicelulares na face abaxial, ca. $0,5 \mathrm{~mm}$ compr.

3. L. cernua

1. Lycopodiella camporum B. Øllg. \& P.G. Windisch, Bradea 5: 24, f. 3. 1987.

Fig. 4-5

Plantas terrícolas. Caule ereto, com ramos laterais dicotomicamente ramificados, fortemente ascendentes e abruptamente curvados em seus ápices, pilosos, tricomas unicelulares hialinos, ca. 1,5 mm compr., microfilos dispostos espiraladamente, patentes a levemente ascendentes no ápice, base do caule com um ramo horizontal arqueado de ápice prolífero, ca. $3 \mathrm{~mm}$ diâm., com microfilos eretos a adpressos, microfilos estreitamente subulados, 1,8-4,7 mm compr. $\times 0,3-0,5 \mathrm{~mm}$ larg., ápice agudíssimo, base adnata ao ramo, longo-decorrente, pilosa na face abaxial, tricomas 
unicelulares, ca. 1,5 mm compr., margem inteira; estróbilos sésseis, pendentes, 0,3-1,5 cm compr. × 0,18-0,25 cm diâm., situados no ápice dos ramos laterais; esporofilos deltóides, 1,5-2,0 mm compr. $\times 0,8-1,2 \mathrm{~mm}$ larg., adpressos, verticilados, ápice longo-acuminado, base obtusa, margem fimbriada; esporângios globosos, anisovalvados.

Material examinado: BRASIL. Mato Grosso do Sul: Corumbá, Serra do Amolar, Morro Alegre, 1758'30,9' S e $59^{\circ} 26^{\prime} 27,1^{\prime}{ }^{\prime} \mathrm{W}, 20 / \mathrm{X} / 2002$, E.L.M. Assis et al. 396 (COR, MBM, SP, UPCB); 20/X/2002, E.L.M. Assis et al. 401(COR).

Material adicional examinado: BOLÍVIA. Santa Cruz: Vellasco, Parque Nacional Noel Kempff Mercado, Huanchacha, 14 31'16"'S e 6044'14"'W, 28/VI/2006, M. Pena-Chocarro et al. 96 (USZ); Vellasco, Serrania La Torre, 13³8'63"'S e 6049'60"'W, 19/V/1994, E. Gutiérrez et al. 985 (USZ).

Distribuição geográfica: Venezuela, Guyana, Guiana Francesa, Colômbia, Peru, Bolívia e Brasil (RR, AM, PA, PI, BA, RO, GO, DF, MT, MS, MG, SP, PR).

Lycopodiella camporum se caracteriza pelos ramos laterais fortemente ascendentes e pelos microfilos com a base pilosa na face abaxial. Esta espécie é muito semelhante a L. сеrnua, diferindo pelas características utilizadas na chave e pelos ramos laterais dicotomicamente ramificados. Segundo Øllgaard \& Windisch (1987), os padrões de ramificação distintos e a ecologia característica desta espécie a torna um táxon facilmente reconhecível e biologicamente bem definido.

Ocorre em regiões montanhosas de cerradões e geralmente em áreas paludosas próximas a córregos, acima de $800 \mathrm{~m}$ de altitude.

2. Lycopodiella caroliniana (L.) Pic.Serm., Webbia 23: 165. 1968.

Lycopodium carolinianum L., Sp. pl. 2: 1104. 1753.

Fig. 6

Plantas terrícolas. Caule prostrado, ca. 1,2 mm diâm.; com ramos laterais dicotomicamente ramificados, glabro, com microfilos dimorfos; dispostos em quatro fileiras; microfilos laterais deltóides, 1,5-2,8 mm compr. ×1,0-1,9 mm larg., ápice agudo, base ineqüiláteral, decorrente, margem inteira; microfilos dorsais deltóides a elípticos, 0,8-2,0 mm compr. $\times$ 0,8-0,9 mm larg., ápice cuspidado, base decorrente, eqüiláteral, glabra, margem inteira; estróbilos eretos, 1,7-3,4 cm compr. $\times 2,6-3,5 \mathrm{~cm}$ diâm., no ápice de um ramo ereto, estramíneo, 6-12 cm compr., glabro, microfilos estreitamente lanceolados, 1,2-4,0 mm compr. $\times 0,5-0,7 \mathrm{~mm}$ larg., esparsos, ápice longo-acuminado, adpressos, margem levemente papilada; esporofilos deltóides a deltóidelanceolados, 3,0-4,0 mm compr. ×1,0-1,8 mm larg., ascendentes a patentes, verticilados, ápice longoacuminado, base obtusa, margem papilada; esporângios reniformes, isovalvados.

Material examinado: BRASIL. Mato Grosso do Sul: Corumbá, Serra do Amolar, Morro Alegre, 1758’30,9'’S e
59²6’27,1’'W, 20/X/2002, E.L.M. Assis et al. 397 (COR, MBM, SP, UPCB).

Distribuição geográfica: Estados Unidos, México, Guatemala, Belize, Honduras, El Salvador, Nicarágua, Panamá, Antilhas, Colômbia, Venezuela, Guiana, Suriname, Guiana Francesa, Equador, Peru e Brasil (AP, AM, RR, PE, BA, DF, MG, RJ, SP, PR, SC, RG).

A presença de um ramos ereto portando em seu ápice um estróbilo ereto, sobre um caule prostrado e a presença de microfilos dimorfos caracterizam esta espécie. É semelhante a Lycopodiella alopecuroides (L.) Cranfill, a qual se diferencia por apresentar, sobre o caule prostrado e o ramo ereto, microfilos monomorfos, abundantes e imbricados.

$\mathrm{Na}$ região de estudo foi encontrada crescendo apenas em regiões montanhosas em áreas de cerrado na margem de córregos com solo encharcado, acima de $750 \mathrm{~m}$.

3. Lycopodiella cernua (L.) Pic.Serm., Webbia 23: 165. 1968. Lycopodium cernum L., Sp. Pl. 1103. 1753.

Fig. 7-8

Plantas terrícolas ou ocasionalmente rupícolas. Caule ereto, com ramos laterais pinadamente ramificados a dicotomicamente ramificados, patentes, não abruptamente curvados em seus ápices, glabros; microfilos dispostos espiraladamente, patentes a ascendentes, base do caule com um ramo horizontal, arqueado de ápice prolífero, ca. $3 \mathrm{~mm}$ diâm., glabro e com microfilos monomorfos, patentes a ascendentes, espiralados; microfilos 2,3-3,4 mm compr. $\times$ 0,17-0,20 mm larg., aciculares a lineares, ápice longoacumindo, base adnata ao ramo, longo-decorrente, glabra ou com esparsos tricomas unicelulares na face abaxial, ca. 0,5 mm compr., margem inteira; estróbilos sésseis, pendentes, 0,3-1,5 cm compr. $\times 0,15-0,25 \mathrm{~cm}$ diâm, situados no ápice dos ramos laterais; esporofilos deltóides, 1,4-2 mm compr. $\times$ 0,8-1,2 mm larg., adpressos, verticilados, ápice longoacuminado, base obtusa, margem fimbriada; esporângios globosos, anisovalvados.

Material examinado: BRASIL. Mato Grosso do Sul: Corumbá, Morro Santa Cruz (MCR), 19²4'49''S e 59²2' 47' 'W, 21/VII/1999, E.L.M. Assis et al. 26 (BHCB, COR); 26/X/1989, V. Pott et AL. (CPAP); 8/VIII/2005, E.L.M. Assis et al. 578 (COR, UPCB).

Material adicional examinado: BOLÍVIA. Santa Cruz: Ichilo, $17^{\circ} 16^{\prime} \mathrm{S}$ e $56^{\circ} 20^{\prime} \mathrm{W}, 23 / \mathrm{XII} / 1992$, M. Nee \& I. Vargas 43279 (USZ); Ñuflo de Chavéz, 24 Km de Concepción, $16^{\circ} 10^{\prime}$ 'S e $62^{\circ} 11^{\prime} \mathrm{W}, 4 / \mathrm{V} / 1995$, J. R. Abbott s.n. (USZ).

Distribuição geográfica: Trópicos e subtrópicos do Velho Mundo, Estados Unidos, México, Guatemala, Belize, Honduras, El Salvador, Nicarágua, Costa Rica, Panamá, Antilhas, Colômbia, Venezuela, Trinidad, Guyana, Suriname, Guiana Francesa, Equador, Peru, Bolívia, Paraguai e Brasil (AM, MA, PE, BA, MS, MT, MG, RJ, SP, PR).

Lycopodiella cernua se caracteriza por apresentar os ramos laterais patentes a levemente ascendentes, o caule glabro e a base dos microfilos também geralmente glabros. 
Tricomas quando presentes na face abaxial da base dos microfilos são esparsos e curtos. Tais características diferenciam esta espécie de L. camporum. Outra espécie muito semelhante a L. cernua é L. pendulina (Hook.) B. Øllg., a qual, segundo Øllgaard (1995), difere por apresentar os ramos laterais pouco ramificados, esporofilos com mais de 2 mm compr. e estróbilos com 3-6 mm largura.
Na região $L$. сеrnua ocorre geralmente em encostas de morros ou em solos perturbados acima de $900 \mathrm{~m}$ de altitude.

Selaginellaceae Willk., Anleit., Stud. Bot. 2: 163. 1854.

Plantas terrícolas, rupícolas ou raramente epífitas. Caule ereto a horizontal, longo-reptante, dicotomicamente ramificado a 1-pinado, com ramos laterais dicotomicamente

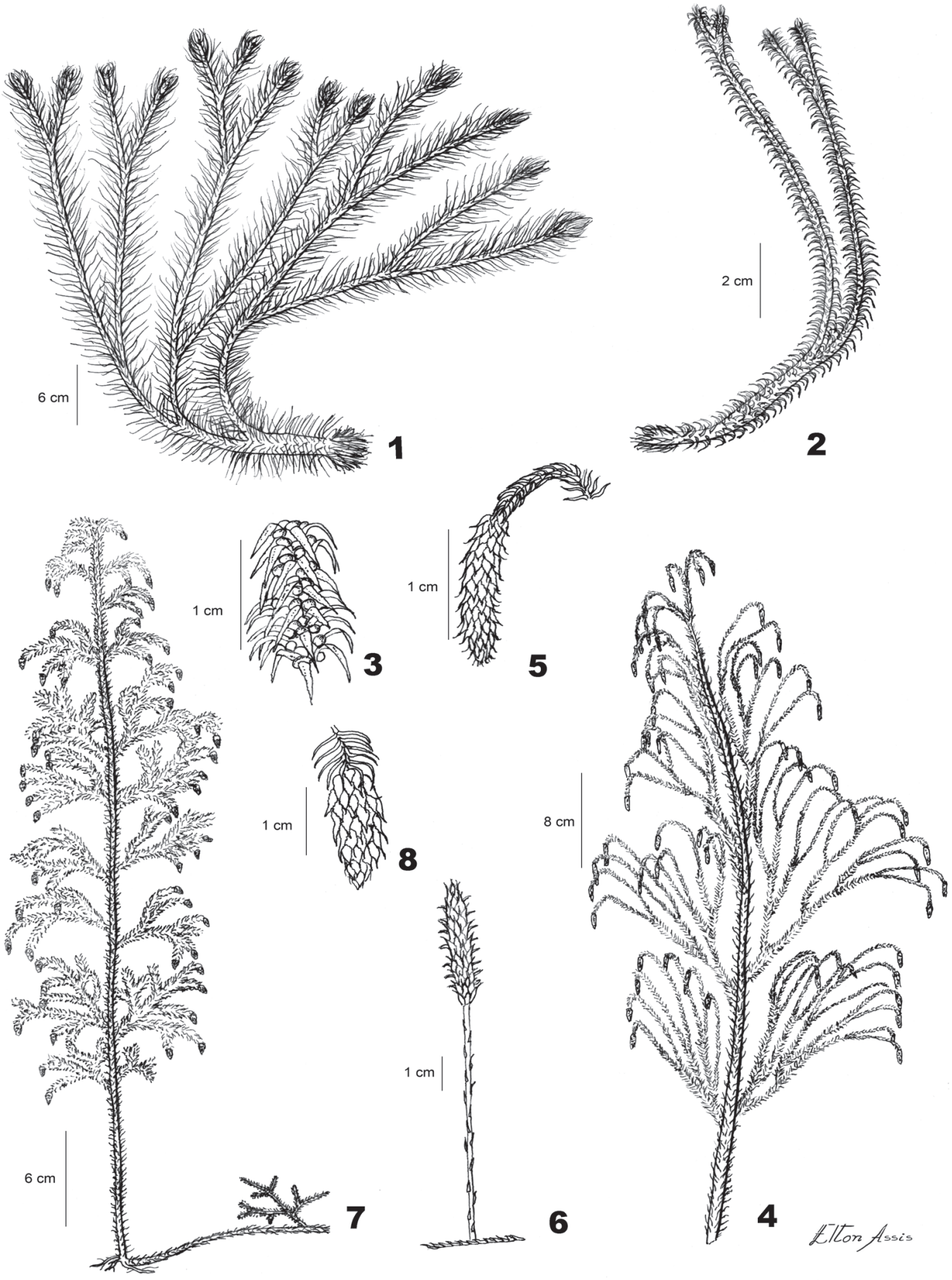

Figuras 1-8. Lycopodiaceae. 1. Huperzia mandiocana (Raddi) Trevis. (E.L.M. Assis et al. 452, COR). 1. Ramo ereto. 2-3. Huperzia reflexa (Lam.) Trevis. (E.L.M. Assis et al. 48, COR). 2. Ramo ereto. 3. Microfilos e esporângios. 4-5. Lycopodiella camporum B. Øllg. \& P.G. Windisch (E.L.M. Assis et al. 401, COR). 4. Ramo ereto. 5. Estróbilo. 6. Lycopodiella caroliniana (L.) Pic.Serm. (E.L.M. Assis et al. 397, COR). 6. Ramo ereto. 7-8. Lycopodiella cernua (L.) Pic.Serm. (E.L.M. Assis et al. 578, COR). 7. Ramo ereto. 8. Estróbilo. 
ramificados, glabros ou com tricomas unicelulares, hialinos, ápice prolífero ou não; microfilos ligulados dispostos espiraladamente, isofilos, ou em quatro fileiras, anisofilos, 2 dois laterais, dois dorsais e um microfilo axilar inserido ventralmente na bifurcação do caule; nervuras simples; rizóforos presentes, ventrais ou dorsais, ramificados; esporofilos modificados, especializados e agregados em estróbilos distintos, localizados no ápice dos ramos, ligulados; esporângios glabros, solitários, situados no lado superior da base dos esporofilos, heterospóricos (megasporângios e microsporângios), 1-loculares, globulares, sésseis, deiscentes por aberturas no ápice de cada esporângio; megasporângios contendo quatro megásporos tetraédrico-globosos, triletes, com uma flange equatorial, em algumas espécies formando tétrades, amarelos a alaranjados, cristados; microsporângios contendo ca. de 100 micrósporos tetraédrico-globosos, triletes, freqüentemente com uma flange equatorial, formando tétrades, amarelos, equinados; $x=8,9,10,12$.

Selaginella P. Beauv., Mag. Encycl. 5: 478.1804 e Prod. Aethéogam. 101. 1805., nom. cons. Tipo: Selaginella spinosa P. Beauv., nom. nov. para Lycopodium selaginoides $\mathrm{L}$. (= Selaginella selaginoides $(\mathrm{L}$. Link).

Selaginella é um gênero com ca. 600-700 espécies, a maioria ocorrendo nos trópicos do Novo Mundo (Fraile et al. 1995; Mickel \& Smith 2004), principalmente do México à Colômbia. No Brasil ocorrem 46 espécies, das quais 16 são endêmicas (Alston et al. 1981).

Na região da borda oeste da borda oeste do Pantanal sulmatogrossense ocorrem seis espécies, crescendo no interior de Florestas Estacionais, encostas de morros ou solos de calcário, de laterítica ou arenosos.

Chave para as espécies de Selaginella da borda oeste do Pantanal sul-matogrossense

1. Microfilos monomorfos, arranjados espiraladamente ao redor do caule

5. S. sellowii

1. Microfilos dimorfos, arranjados em quatro fileiras ao redor do caule

2. Caule articulado; rizóforos dorsais

3. Face abaxial do caule sulcado; microfilos axilares com duas aurículas 6. S. sulcata

3. Face abaxial do caule não sulcado; microfilos axilares com uma única aurícula 4. S. marginata

2. Caule não articulado; rizóforos ventrais

4. Caule prostrado, margem de todos os microfilos fortemente hialina; rizóforos com até $0,2 \mathrm{~mm}$ diâm.

1. S. chiquitana

4. Caule ereto, margem de todos os microfilos levemente hialina; rizóforos com mais de $0,2 \mathrm{~mm}$ diâm.

5. Microfilos da base do caule avermelhados; microfilos dorsais longo-ciliados 3. S. erythropus

5. Microfilos da base do caule pardos a castanho escuros; microfilos dorsais curto-ciliados .... 2. S. convoluta

\section{Selaginella chiquitana M. Kessler, A.R. Sm \& M. Lehnert.,} Edinburgh J. Bot. 63(1): 85-93. 2006.

Fig. 9-13

Plantas rupícolas. Caule prostrado, ca. 0,4 mm diâm., verde-estramíneo, glabro, monostélico, não flageliforme, não articulado, não estolonífero, face abaxial não sulcada; rizóforos ventrais presentes em toda extensão do caule, ca. 0,2 mm diâm.; microfilos dimorfos, dispostos em 4 fileiras, anisofilos, membranáceos, convolutos quando secos; microfilos laterais oblongos, assimétricos, 1,7-2,3 mm compr. $\times 0,8-0,9 \mathrm{~mm}$ larg., imbricados ou não, ápice agudo a obtuso, basifixos, não auriculados, margem fortemente hialina, longociliada na porção proximal e denticulada na distal; microfilos dorsais lanceolados, simétricos, 0,9-1,3 mm compr. $\times 0,4-0,5$ mm larg., ápice acuminado, basifixos, com uma aurícula curta no lado externo, curto-ciliada, margem fortemente hialina, curto-ciliada na porção proximal e serrilhada na distal; microfilos axilares oblongos, simétricos, 1,4-1,9 mm compr.x 0,4-0,6 mm larg., ápice agudo, basifixos, margem fortemente hialina, longo-ciliada na porção proximal e denticulada na distal; estróbilos quadrangulares, 3,0-4,5 mm compr.; esporofilos largamente deltóides, simétricos, 1,0-1,2 mm compr.×0,7-0,9 mm larg., ápice acuminado, basifixos, margem inteira na porção proximal e denticulada na distal; megasporângio globoso, megásporos reticulados, cristas baixas; microsporângios globosos, micrósporos tetraédricoglobosos, triletes, equinados.

Material examinado: BRASIL. Mato Grosso do Sul: Corumbá, Morro Urucum (Nascente do córrego Banda Alta), 19¹1'15.148"'S e 57³4'53.081"'W, 26/VII/2001, E.L.M.Assis 261 (BHCB, COR); 3/XI/2001, E.L.M. Assis 301 (COR, BHCB, SP, UPCB).

Distribuição geográfica: Bolívia e Brasil (MS).

Selaginella chiquitana se caracteriza por apresentar todos os microfilos com a margem fortemente hialina, com a base longo-ciliada, exceto os dorsais que possuem uma aurícula curta no lado externo. Apesar do material tipo desta espécie não apresentar esporofilos, as características referentes aos microfilos são idênticas às do material estudado.

Esta espécie se assemelha muito a S. arroyana M. Kessler, A.R. Sm \& M. Lehnert., a qual difere por apresentar a base do microfilo axilar alargada e a base do lado acroscópico dos microfilos laterais menos arredondados que nesta espécie. Segundo Kessler et al. (2006), S. arroynana costuma apresentar os microfilos laterais, quando secos, 
enrolados sobre o caule, característica comum também em S. chiquitana.

Na região ocorre principalmente como rupícola, sobre paredões rochosos ou areníticos extremamente úmidos, no interior de Floresta Estacional Semidecidual, acima de $850 \mathrm{~m}$.

2. Selaginella convoluta (Arn.) Spring in Mart., Fl. Bras. 1(2): 131. 1840.

Lycopodium convolutum Arn., Mem. Wern. Nat. Hist. Soc. 5: 199.1824

Fig. 14-16

Plantas terrícolas. Caule ereto, ca. 1 mm diâm., ca. $20 \mathrm{~cm}$ compr., monostélico, glabro, castanho-escuro, não articulado, não flageliforme, não estolonífero, face abaxial não sulcada; rizóforos ventrais, restritos à base do caule, ca. $0,5 \mathrm{~mm}$ diâm., filiformes; microfilos dimorfos, dispostos em 4 fileiras, anisofilos, coriáceos, os basais pardos a castanho-escuros; microfilos laterais oblongos, assimétricos, 3,8-4,2 mm compr. $\times 1,8-2,0 \mathrm{~mm}$ larg., imbricados, ápice acuminado, basifixas com 2 aurículas curtas, a basioscópica mais larga que a acroscópica, curto-ciliadas, margem levemente hialina, curtociliada na porção proximal e denticulada na distal; microfilos dorsais ovais a oval-oblongos, assimétricos, 2,8-3,0 mm compr. $\times 1,0-1,3 \mathrm{~mm}$ larg., imbricados, ápice curto-aristado, basifixos, com 1 aurícula, curto-ciliada, margem levemente hialina, curto-ciliada na porção proximal e denticulada na distal; microfilos axilares semelhantes aos laterais; estróbilos quadrangulares, 1-3 cm compr.; esporofilos deltóides, simétricos, 2,0-2,2 mm compr. ×1,2-1,5 mm larg, ápice acuminado, base com 1 aurícula reduzida; margem hialina, denteada; megasporângios globosos, megásporos reticulados, cristas altas; microsporângios reniformes, micrósporos tetraédrico-globosos.

Material examinado: BRASIL. Mato Grosso do Sul: Corumbá, Estrada Parque (Bancada Laterítica), 19¹0'02"S e 57³3'31'”, 12/VI/2001, E.L.M. Assis \& I.H. Ishii 238 (BHCB, COR, MBM, SP, UPCB).

Material adicional examinado: BOLÍVIA. Santa Cruz: Vellasco, $5 \mathrm{~km}$ de Cerro Pelao, 14³2'35"'S e 61 ${ }^{\circ} 29^{\prime} 52^{\prime \prime} \mathrm{W}, 22 /$ I/1997, J. Guillen et al. 283 (USZ); Nuflo de Chavéz, Estância San Miguelito, $17^{\circ} 09^{\prime} \mathrm{S}$ e $61^{\circ} 40^{\prime} \mathrm{W}, 7 / \mathrm{IV} / 1995$, A. Fuentes $741 B$ (USZ).

Distribuição geográfica: México, Guatemala, Honduras, Cuba, Hipaniola, Argentina, Paraguai e Brasil (PI, CE, PE, BA, GO, MS, MG, ES, RJ, SP).

Esta espécie se caracteriza por apresentar o caule ereto e os ramos formando rosetas e recurvados quando secos, além dos microfilos laterais da base do caule, pardos a castanho-escuros. Selaginella convoluta é semelhante a S. lepidophylla (Hook. \& Grev.) Spring, S. novoleonensis Hieron., e $S$. ribae Valdespino, as quais diferem por apresentar o caule pubescente e os microfilos laterais largamente ovais ou oval-deltóides, sendo todas as três endêmicas do México (Mickel \& Smith 2004).

A presença e quantidade de aurículas na base dos microfilos laterais nesta espécie são bastante variáveis. Mickel
\& Smith (2004), descrevem que, para os espécimes do México, esta espécie é distingüível por apresentar uma única aurícula na base dos microfilos laterais, apesar da figura mostrar duas aurículas curtas, tal qual o presente material, já os espécimes estudados por Hirai \& Prado (2000) para São Paulo, Brasil, os microfilos laterais não apresentaram aurículas.

$\mathrm{Na}$ região esta espécie é somente encontrada em bancadas lateríticas, em locais sombreados e com uma grande quantidade de húmus, ou em locais abertos. No período seco os ramos se enrolam convolutamente, abrindo-se novamente em períodos de umidade mais elevada. Ocorre acima de $120 \mathrm{~m}$ de altitude.

3. Selaginella erythropus (Mart.) Spring, Fl. Bras. 1(2): 125. 1840.

Lycopodium erythropus Mart., Icon. Select. Pl. Crypt. Bras. 39. 1834.

Fig. 17-19

Plantas terrícolas. Caule ereto, ca. 1,5 mm diâm., ca. $30 \mathrm{~cm}$ compr., monostélico, glabro, avermelhado antes da primeira ramificação, não articulado, não flageliforme, estolonífero, face abaxial não sulcada; rizóforos ventrais, restritos a base do caule, ca. 0,3 mm diâm., filiformes; microfilos dimorfos, dispostos em 4 fileiras, anisofilos, herbáceos, os basais avermelhados na margem; microfilos laterais deltóides a ovallanceolados, assimétricos, 2,0-3,2 mm compr. ×1,4-2,0 mm larg., imbricados ou não, ápice acuminado, basifixos, não auriculados, margem levemente hialina, longo-ciliada na porção proximal e serrilhada na distal; microfilos dorsais deltóide-lanceolados a ovais, simétricos, 2,0-3,0 mm compr. $\times 0,8-1,0 \mathrm{~mm}$ larg., não imbricados, ápice curto-aristado, basifixos, não auriculados, margem levemente hialina, longociliada na porção proximal e serrilhada na distal; microfilos axilares lanceolados, simétrico, 0,8-2,0 mm compr. $\times 0,4-1,0 \mathrm{~mm}$ larg., ápice acuminado, basifixos não aurículados, margem levemente hialina, longo-ciliada na porção proximal e serrilhada na distal; estróbilos quadrangulares, 2,0-4,0 mm compr.; esporofilos deltóides, simétricos, 1,0-1,3 mm compr. $\times 0,4-0,6 \mathrm{~mm}$ larg, ápice curto-aristado, basifixos, não auriculados, margem não hialina, ciliada na porção proximal e serrilhada na distal; megasporângios globosos, megásporos tetraédrico-globosos, triletes, amarelos; microsporângios reniformes, micrósporos tetraédricoglobosos, triletes, verrucosos, castanho-escuros.

Material examinado: BRASIL. Mato Grosso do Sul: Corumbá, Serra do Amolar, Morros Dourados, $18^{\circ} 03$ '2.2''S e 57'29'29.6"W, 19/X/2002, E.L.M. Assis et al. (COR); Retiro Rumo Oeste, 1748'15,2”S e 57 40'31,1”'W, 20/X/2002, E.L.M. Assis et al. 409 (COR, MBM, SP, UPCB).

Material adicional examinado: BOLÍVIA. Santa Cruz: Velasco, Parque Nacional Noel Kempf Mercado, Campamento Vaz Gómez, 1448’00”'Se 60²3’00”W, 4/V/1993, L. Arroyo et al. 205 (USZ).

Distribuição geográfica: Costa Rica, Colômbia, Equador, Peru, Bolívia e Brasil (BA, CE, PI, MT, MS, MG, RJ).

Selaginella erythropus se caracteriza por apresentar a 
parte proximal do caule (antes da primeira ramificação) e os microfilos situados nesta região, avermelhados, bem como pelos microfilos e esporofilos com cílios longos e microfilos com base não auriculada. Esta espécie é muito próxima de $S$. viticulosa Klotzch, (Costa Rica, Panamá, Colômbia, Venezuela) difere, no entanto, por esta espécie apresentar os microfilos laterais oblongos e o caule e os microfilos não avermelhados (Fraile 1995).

Na região cresce em solos arenosos do cerrado em locais abertos e em campos inundáveis, acima de $100 \mathrm{~m}$.

4. Selaginella marginata (Humb. \& Bonpl. ex Willd.) Spring, Flora 21: 1994 (1838).

Lycopodium marginatum Humb. \& Bonpl. ex Willd., Sp. Pl. $5: 41(1810)$

Fig. 20-22

Plantas terrícolas. Caule horizontal, prostrado com ramos ascedentes, ca. 1 mm diâm., monostélico, glabro, estramíneo, articulado, não flageliforme, não estolonífero, face abaxial não sulcada; rizóforos dorsais, presentes em toda extensão do caule, ca. 0,5 mm diâm., não filiformes; microfilos dimorfos, dispostos em 4 fileiras, anisofilos, herbáceos; microfilos laterais oval-lanceolados a oblongos, assimétricos, 2,0-2,5 (-3) cm compr. $\times 0,8-1,8 \mathrm{~mm}$ larg., freqüentemente espaçados entre si, ápice agudo, base peltada, com uma aurícula longa paralela ao caule, ciliada, margem levemente hialina, curto-ciliada na porção proximal e denticulada na distal; microfilos dorsais ovais, assimétricos, 2,0-3,0 mm compr. $\times 1,0-1,2 \mathrm{~mm}$ larg., ápice acuminado, basifixos, margem levemente hialina, curto-ciliada na porção proximal e denticulada na distal; microfilos axilares deltóidelanceolados, simétricos, 2,0-2,5 mm compr. $\times 0,5-0,7 \mathrm{~mm}$ larg., ápice agudo a obtuso, base peltada, com uma aurícula longodecorrente, às vezes curvadas, margem levemente hialina, denticulada; estróbilos quadrangulares, 0,8-1,8 cm compr.; esporofilos deltóides, simétricos, 2,0-2,5 $\mathrm{mm}$ compr. $\times$ 1,0-1,2 cm larg., ápice acuminado, base curto-auriculada, margem hialina, serrilhada; megasporângios tertaédricoglobosos, megásporos esferoidais com cristas altas, reticuladas, alvas; microsporângios reniforme-globosos, micrósporos equinados.

Material examinado: BRASIL. Mato Grosso do Sul: Corumbá, Ladário, Estrada Parque, próximo a Faz. Banda Alta, 19¹0'02''S e 57³3'31'W, 30/VII/1999, E.L.M. Assis et al. 52 (BHCB, COR); Corumbá, Morro Urucum, 19¹1'15.148"'S e 5734'53.081'”, 15/III/2001, E.L.M. Assis 101 (COR, UPCB); Estrada Parque, Bancada Laterítica, $19^{\circ} 10^{\prime} 02^{\prime \prime} \mathrm{S}$ e $57^{\circ} 33^{\prime} 31^{\prime \prime} \mathrm{W}, 12 / \mathrm{VI} / 2001$, E.L.M. Assis et al. 241 (COR, UPCB); Morro Santa Cruz (MCR), 19²4'49”'S e 59²2'47”'W, 5/VII/2005, E.L.M. Assis 607 (COR, SP).

Material adicional examinado: BOLÍVIA. Santa Cruz: Velasco, Parque Nacional Noel Kempf Mercado, $14^{\circ} 37^{\prime} \mathrm{S}$ e $60^{\circ} 42^{\prime} \mathrm{W}, 25 / \mathrm{VI} / 1994$, L. Arroyo et al. s.n (USZ); Ichilo, parque Nacional de Amboró, $17^{\circ} 33^{\prime} \mathrm{S}$ e $63^{\circ}$ 52’W, 1/VI/1998, M. Nee 49583 (USZ).
Distribuição geográfica: México, Venezuela, Uruguai, Argentina, Paraguai, Bolívia e Brasil (MA, PI, BA, MT, MS, RJ, SP, PR, SC, RS).

Selaginella marginata se caracteriza por apresentar os microfilos laterais peltados com uma longa aurícula na base paralela ao caule, ciliada, e os microfilos axilares peltados com uma aurícula longo-decorrente. Estas características a distinguem das outras espécies de Selaginella encontradas na região.

Esta espécie é semelhante a S. silvestris Asplund (México, América Central, Colômbia, Venezuela, Equador, Peru, Bolívia) a qual não apresenta os microfilos laterais e axilares auriculados (Somers \& Moran 1995).

$\mathrm{Na}$ região cresce em locais abertos como bancadas lateríticas, ou no interior e borda de floretas estacionais, preferindo ambientes mais secos ou, ainda, na margem de córregos e beira de trilhas, acima de $100 \mathrm{~m}$.

5. Selaginella sellowii Hieron., Hedwivigia 39: 306. 1900.

Fig. 23-25

Plantas terrícolas, raramente rupícolas. Caule horizontal, prostrado, ca. $6 \mathrm{~mm}$ diâm., castanho-escuro, glabro, monostélico, face abaxial não sulcada; rizóforos presentes em toda extensão do caule, ca. 3 mm diâm., não filiformes; microfilos monomorfos, dispostos espiraladamente sobre o caule, isofilos, coriáceos, 1,3-2,0 mm compr. $\times 0,2-0,4 \mathrm{~mm}$ larg., linear-lanceolados, ápice curto-aristado, basifixos, não auriculados, margem levemente hialina, longo-ciliada na porção proximal e denteada na distal; estróbilos quadrangulares ca. $6 \mathrm{~mm}$ compr.; esporofilos deltóides, 2,0-2,6 mm compr. $\times 0,6-0,8 \mathrm{~mm}$ larg., ápice curto-aristado, basifixos, curto-auriculada; margem curto-ciliada na porção proximal e serrilhada na distal; megasporângios tertaédricoglobosos, megásporo esferoidal, levemente equinados; microsporângios reniforme-globosos, micrósporo tetraédrico-globoso, trilete, glanuloso, alaranjado.

Material examinado: BRASIL. Mato Grosso do Sul: Corumbá, Estrada Parque, 15/III/2001, E.L.M. Assis 108 (BHCB, COR); Br 262 (Faz. Isulina Xavier), 11/VIII/2005, E.L.M. Assis \& A. Takahasi 584 (COR, BHCB, SP, UPCB); Estrada Parque, (Bancada Laterítica), 19 ${ }^{\circ} 10^{\prime} 02^{\prime \prime} \mathrm{S}$ e 57'33'31”'W, 3/XI/2005, E.L.M. Assis 611 (COR, UPCB).

Material adicional examinado: BOLÍVIA. Valegrande: El Estanque, $18^{\circ} 56^{\prime}$ 'S e 648,5W, 24-27/XII/1990, I. G. Vargas 874 (USZ).

Distribuição geográfica: México, Cuba, Colômbia, Venezuela, Equador, Peru, Uruguai, Argentina, Paraguai, Bolívia e Brasil (BA, MT, MS, ES, RJ, SP, RS).

Selaginellla selowii se caracteriza por apresentar os microfilos monomorfos, isofilos, dispostos espiraladamente sobre o caule. Estas características a distinguem de todas as outras espécies da região.

Selaginella sartorii Hieron. é uma das espécies mais semelhantes, a qual difere por apresentar os microfilos mais imbricados, pubescentes e não ciliados na margem (Alston 1981). 
Esta espécie pode apresentar hábitos variáveis dependendo da distribuição geográfica. Segundo Hirai \& Prado (2000), no estado de São Paulo ocorre como epífita sobre troncos em decomposição. Na região estudada ocorre principalmente como terrícola em bancadas lateríticas, formando densos "tapetes verdes" em períodos chuvosos, já em períodos de seca, os microfilos ficam adpressos ao caule, perdendo a pigmentação verde, sugerindo um mecanismo poiquilohídrico de sobrevivência. Ocorre acima de $150 \mathrm{~m}$ de altitude.

6. Selaginella sulcata (Desv. ex Poir.) Spring ex Mart., Flora 2: 126.1837.

Lycopodium sulcatum Desv ex Poir. Inlam., Encycl. Suppl. 3:549. 1814.

Fig. 26-28

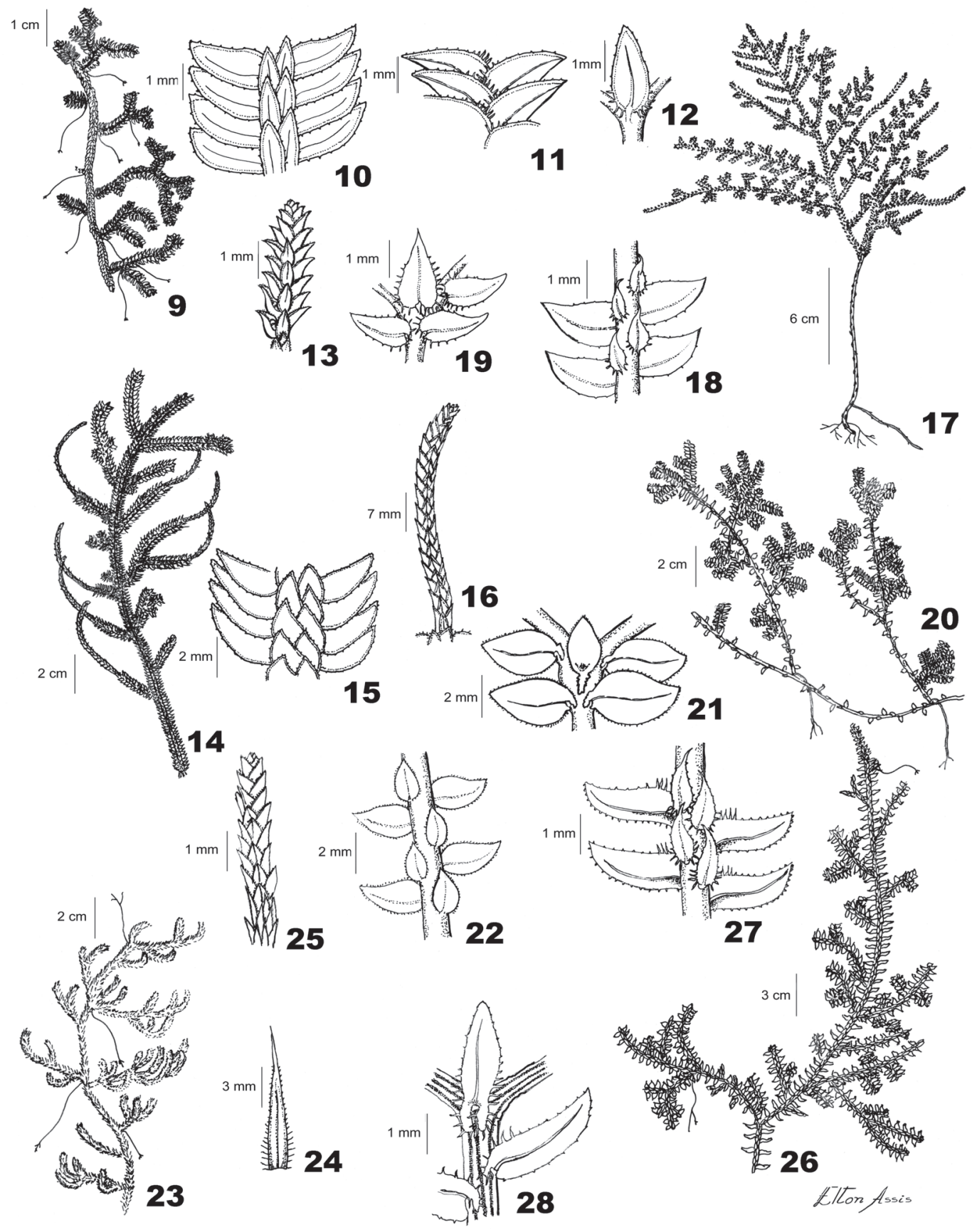

Figuras 9-28. Selaginellaceae. 9-13. Selaginella chiquitana M. Kessler (E.L.M. Assis 301, COR). 9. Ramo prostrado. 10. Microfilos dorsais e laterais. 11. Face abaxial dos microfilos laterais. 12. Microfilo axilar. 13. Estróbilo. 14-16. Selaginella convoluta (Arn.) Spring in Mart. (E.L.M. Assis \& I.H. Ishii 238, COR). 14. Ramo ereto. 15. Microfilos dorsais e laterais. 16. Estróbilo. 17-19. Selaginella erythropus (Mart.) Spring (E.L.M. Assis et al. 409, COR). 17. Ramo ereto. 18. Microfilos dorsais e laterais. 19. Microfilo axilar. 20-22. Selaginella marginata (Humb. \& Bonpl. ex Willd.) Spring (E.L.M. Assis 607, UPCB). 20. Ramo ascendente. 21. Microfilos axilar e laterais . 22. Microfilos dorsais. 23-25. Selaginella sellowii Hieron. (E.L.M. Assis 611, COR). 23. Ramo prostrado. 24. Microfilo. 25. Estróbilo. 26-28. Selaginella sulcata (Desv. ex Poir.) Spring ex Mart. (E.L.M. Assis et al. 368, COR). 26. Ramo ereto. 27. Microfilos dorsais e laterais. 28. Microfilo axilar e microfilos laterais. 
Plantas terrícolas. Caule inicialmente ereto tornando-se prostrado posteriormente, ca. $1 \mathrm{~mm}$ diâm., polistélico, glabro, estramíneo, articulado, flageliforme, não estolonífero, face abaxial sulcada; rizóforos dorsais, presentes em toda extensão do caule, ca. $0,5 \mathrm{~mm}$ diâm., não filiforme; microfilos dimorfos, dispostos em 4 fileiras, anisofilos, herbáceos; microfilos laterais oblongo-lancelados, assimétricos, 2,0-3,0 mm compr. $\times 1,0-1,6 \mathrm{~mm}$ larg., freqüentemente espaçados entre si, ápice agudo a acuminado, basifixos, com uma aurícula no lado acroscópico extendendo-se sobre o caule, longo-ciliada e uma outra no lado basioscópico vestigial, ciliada, margem levemente hialina, longo-cilada na porção proximal e denticulada na distal; microfilos dorsais ovais a oval-lanceolados, assimétricos, 1,4-2,3 mm compr.x 0,8-1,2 mm larg., ápice longo-acuminado, base peltada com uma aurícula curto-decorrente, curto-ciliada, margem levemente hialina, longo-ciliada na porção proximal e serrilhada na distal; microfilos axilares oval-lanceolados, simétricos, 2,5-3,0 mm compr. $\times 0,5-0,7 \mathrm{~mm}$ larg., ápice agudo a longo-acuminado, basifixos, base biauriculada, auriculas longas, ás vezes curvadas, longo-ciliadas, margem levemente hialina, longo-ciliada na porção proximal e denticulada na distal; estróbilos quadrangulares, 4,0-6,5 mm compr.; esporofilos deltóides, simétricos, 0,9-1,1 mm compr.x 0,4-0,6 mm larg., ápice longo-acuminado, base curtoauriculada, margem hialina, serrilhada; megasporângios tetraédrico-globosos, megásporos esferoidais com cristas altas, reticuladas, alvas; microsporângios reniformeglobosos, micrósporos equinados.

Material examinado: BRASIL. Mato Grosso do Sul: Corumbá, Serra do Amolar, Morro do Sucuri, 18³5'27,6"S e 57²2'51,6' 'W, 18/X/2002, E.L.M. Assis 368 (COR); Jatobazinho, Córrego Taquaral, 4/XI/2004, E.L.M. Assis et al. 496 (COR, MBM, SP, UPCB).

Material adicional examinado: BOLÍVIA. Chuquisaca: Sud Cinti, ao redor de La Finca La Redonda, $10^{\circ} 46^{\prime} 19^{\prime \prime} \mathrm{S}$ e 6417'45”'W, 23/V/1995, B. Holst 4775 (USZ).

Distribuição geográfica: Suriname, Argentina, Paraguai, Bolívia e Brasil (CE, PA, PE, BA, MS, MT, MG, ES, RJ, SP, PR, SC, RS).

Selaginella sulcata se caracteriza por apresentar a face abaxial do caule sulcado, os microfilos axilares com duas longas aurículas, retas ou curvadas, e longo-ciliadas, além dos microfilos laterais com a aurícula no lado acroscópico curvada e mais longa que a do lado basioscópico, o que a difere das outras espécies da região. Selaginella diffusa (C. Presl) Spring, é muito próxima de S. sulcata, diferindo por apresentar os cílios multicelulares na margem dos microfilos (Alston 1981).

Na região é comum em locais abertos de solo arenoso, ou nas proximidades de córregos, acima de $150 \mathrm{~m}$.

\section{Agradecimentos}

Somos gratos ao CAPES, pela bolsa de Mestrado concedida ao primeiro autor, ao programa de Pós-graduação em Botânica da UFPR, e ao herbário COR, por facilitar o acesso aos materiais e pelo auxílio nas atividades de campo.

\section{Referências bibliográficas}

Adamoli, J. 1982. O Pantanal matogrossense e suas relações fitogeográficas com o Cerrado e discussão sobre o conceito de complexo do Pantanal. Pp. 109-119. In: Anais do XXXIII Congresso Nacional de Botânica. Terezina 1981. Piauí.

Alston, A.H.G.; Jermy, A.C. \& Rankin, J.M. 1981. The genus Selaginella in tropical South America. Bulletin of the British Museum (Natural History), Botany 9: 233-330.

Bortolotto, I.M.; Damasceno Júnior, G.A. \& Isquierdo, S.W.G. 1999. Caracterização das unidades fitofisionômicas da microbacia da Baia Negra, Corumbá e Ladário, MS. Pp. 60-64. In: Anais do Simpósio sobre recursos naturais e sócio-econômicos do Pantanal - Manejo e Conservação. Corumbá 1996. Mato Grosso do Sul, Embrapa Pantanal.

Cantino, P.D.; Doyle, J.A.; Graham, S.W.; Judd, W.S.; Olmstead, R.G.; Soltis, D.E.; Soltis, P.S. \& Donoghue, M.J. 2007. Towards a phylogenetic nomenclature of Tracheophyta. Taxon 56: 822-846.

Fraile, M.E. 1995. Selaginellaceae. Pp. 41. In: R.C. Moran \& R. Riba (eds.). In: Psilotaceae a Salviniaceae. G. Davidse, M. Sousa, \& S. Knapp, (eds.) Flora Mesoamericana. Universidad Nacional Autónoma de México, Ciudad de México. v.1.

Fraile, M.E.; Somers, P. Jr. \& Moran, R.C. 1995. Selaginella. Pp. 22-42. In: R.C. Moran \& R. Riba (eds.). In: Psilotaceae a Salviniaceae. G. Davidse, M. Sousa, \& S. Knapp, (eds.) Flora Mesoamericana. Universidad Nacional Autónoma de México, Ciudad de México. V. 1.

Hirai, R.Y. \& Prado, J. 2000. Selaginellaceae Willk. No Estado de São Paulo, Brasil. Revista Brasileira de Botânica 23: 313-339.

Kessler, M.; Smith; A.R. \& Lehnert, M. 2006. Four new species of Selaginella (Pteridophyta - Selaginellaceae) From Bolivia. Edinburgh Journal of Botany 63: 85-93.

Korall, P. \& Kenrich, P. 2002. Phylogenetic relationships in Selaginellaceae based on $r b c l$ sequences. American Journal of Botany 89: 506-517.

Korall, P.; Kenrich, P. \& Therrien, J.P. 1999. Phylogeny of Selaginellaceae: evaluation of generic/subgeneric relationships based on $r b c l$ gene sequences. International Journal of Plant Sciences 160: 585-594.

Mickel, J.T. \& Smith, A.R. 2004. The pteridophytes of Mexico. Memoirs of the New York Botanical Garden. New York.

Nessel, H. 1927. Die Bärlappgewächse (Lycopodiaceae). G. Fischer, Jena.

Nessel, H. 1955. Lycopodiaceae In: F.C. Hoehne (ed.) Flora Brasilica II:II: $1-131$

Øllggard, B. 1987. A revised classification of the Lycopodiaceae s. lat. Opera Botanica 92: 153-178.

Øllgaard, B. 1995. Lycopodiacae. Pp. 5-22. In: G. Davidse; M. Sousa, \& S. Knapp (eds.). Flora Mesoamericana. Psilotaceae a Salviniaceae, Universidad Nacional Autónoma de México, Ciudad de México.

Øllggard, B. \& Windisch, P.G. 1987. Sinopse das Licopodiáceas do Brasil. Bradea 5: 1-43.

Pichi-Sermolli, R.E.G. 1996. Authors of scientific names in Pteridophyta. Kew, Royal Botanic Gardens.

Pott, V.J. \& Pott, A. 1997. Checklist das macrófitas aquáticas do Pantanal, Brasil. Acta Botanica Brasilica 11: 215-227.

Pott, V.J. \& Pott, A. 2000. Plantas aquáticas do Pantanal. Brasília.

Pryer, K.M.; Schneider, H.; Smith, A.R.; Cranfill, R.; Wolf, P.G.; Hunt, J.S. \& Sipes, S.D. 2001. Horsetails and ferns are a monophyletic group and the closest living relatives to seed plants. Nature 409: 618-622.

Somers, P. Jr. \& Moran, R.C. 1995. Selaginella. Pp. 28. In: R.C. Moran\& R. Riba (eds.). In: Psilotaceae a Salviniaceae. G. Davidse, M. Sousa, \& S. Knapp, (eds.) Flora Mesoamericana. Universidad Nacional Autónoma de México, Ciudad de México. v. 1.

Tryon, R.M. \& Tryon, A.F. 1982. Ferns and allied plants, with special reference to Tropical America. New York, Spring Verlag. 